\title{
Infants Teething Problems and Mothers' Beliefs in South East of Iran
}

\author{
Ghasem Miri-Aliabad (iD) ${ }^{1,}$, Ali Khajeh (iD ${ }^{1}$ and Alireza Teimouri (ii) ${ }^{2}$ \\ ${ }^{1}$ Department of Pediatrics, Children and Adolescent Health Research Center, Zahedan University of Medical Sciences, Zahedan, Iran \\ ${ }^{2}$ Children and Adolescent Health Research Center, Zahedan University of Medical Sciences, Zahedan, Iran \\ "Corresponding author: Department of Pediatrics, Children and Adolescent Health Research Center, Zahedan University of Medical Sciences, Zahedan, Iran. Email: \\ ghmiri1357@gmail.com
}

Received 2017 October 08; Revised 2020 July 26; Accepted 2021 February 07.

\begin{abstract}
Background: Teething is a physiological process, which usually does not cause problems. A variety of symptoms are ascribed to infant teething, despite little evidence to support such belief. The wrong beliefs and misconceptions about the symptoms of teething may present serious risks to infants.

Objectives: This study aims for determination of the mothers' attitude about the symptoms and signs of infants teething.

Methods: Data collection was done using a questionnaire, containing demographic information of the respondents as well as a number of 20 questions about the signs and symptoms of teething. In this study, 220 questionnaires were completed by mothers having 6 - 30 months' children, with at least one deciduous tooth.

Results: The mean age of the mothers was $28.26 \pm 5.10$ years old. Mean of the first deciduous tooth eruption in them was $7.16 \pm 1.60$ month. All mother associated, at least, one symptom with teething. In this study, mothers' beliefs were as follows: gum rubbing (91\%), biting objects (86\%), restlessness and irritability (84\%), fever (75\%), drooling (70\%), and diarrhea (62\%).

Conclusions: Regarding that symptoms such as fever, diarrhea, and restlessness and irritability are attributed to teething, this can distract parents from serious illnesses, leading to diagnosis and treatment delay.
\end{abstract}

Keywords: Teething, Infants, Mothers, Symptoms

\section{Background}

Tooth eruption is a practice, in which tooth germ moves from its first place within alveolar bone, to its final location within the oral cavity, so owning true teeth one in every of the nice innovations of vertebrates (1). In this process, it seems that, the dental follicles, as rich source of eicosanoids, cytokines, and growth factors are highlighted and have significant effects (2). In gingival crevicular fluid, where the primary tooth forms, the level of inflammatory cytokines such as IL-1B, IL-8, TNF-alpha increases and this can explain some of the signs and symptoms of teething (3).

Based on the majority of biological data, tooth starts developing within a normal range of age (4). Typically, an infant's first tooth erupts between the ages of 4-10 months, and a full complement of 20 deciduous teeth erupts within 30 months. Therefore, between 6 and 30 months of age, the average child erupts approximately one tooth per month, closely coinciding with a time in which infants are known to undergo recurrent minor diseases and rapid changes in development (5). The general health of infants as a result of deciduous teeth eruption dates back to 5000 years ago. In addition, symptoms such as fever, diarrhea, seizures, vomiting, neuralgia, weight loss, toxemia, tonsillitis, paralysis, meningitis, etc. have been related by our ancestors to teething (6).Teething leads to severe symptoms such as diarrhea, vomiting, eczema, bronchial secretions, and seizures, and some pediatricians have shown and confirmed crying fits and strabismus (7). Macknin and colleagues demonstrated that biting, drooling, gum rubbing, sucking, irritability, waking up, rubbing the ear, acne, loss of appetite for solid foods and body temperature with tooth eruption (8). the frequency of death was very high due to the infants teething during 16 - 19 century AD, (6). Typically, ontogenesis isn't related to vital discomfort in infants and youngsters and is thought as a natural and unhazardous development (9). Despite this, wrong beliefs and misconceptions exist inside mothers and health staffs about the infants teething (10-12). On the one hand, these wrong beliefs might inhibit correct and acceptable copping with some frequent biological process things throughout the. On the other hand, they may delay proper and serious diagnosis $(5,13)$. 


\section{Objectives}

The present study aimed to investigate the common beliefs among the mothers about infants' teething.

\section{Methods}

This descriptive-analytical study conducted to determine the mothers' beliefs about the signs and symptoms of infants' teething. Individual illegible to be included in the study were mothers with infants, from 6 to 30 months of age, who had at least one deciduous tooth. The study performed between February 2017 and February 2018.

Data collection performed using a questionnaire including demographic information as well as a number of 20 signs and symptoms, properly or improperly, attributed to teething by mothers. In this study, 220 questionnaires were completed by mothers having 6 - 30 months' children, with at least one deciduous tooth. For illiterate mothers, the questions were read in simple and understandable forms, and then their answers were written in the questionnaires by the questioner. After completion of the questionnaires by the mothers, the obtained information was entered into SPSS 20 and for the quantities and qualitative variables mean plus standard deviation and frequency or percentages presented as descriptive statistics respectively. For the analysis, Pearson Chi square test applied. The level of significance considered 0.05 .

\section{Results}

The mean age as well as age group of the mother are presented in Table 1. In addition, the number of children in each age group is provided in Table 2. Over half of the mothers were between 20 to 30 years old. The age range of the infants and children of the participated mothers were between 6 to 30 months old with mean age of $6.8716 .79 \pm$ months. In addition, 107 subjects (49\%) were boy and 113 subjects (51\%) were girl, indicating no significant statistical difference $(P>0.05)$. The mean of tooth eruption time in these infants were $7.16 \pm 1.60$ months (ranging from 4 to 14 months). Among the mothers, 24\% had one child and 2\% had seven children.

\begin{tabular}{lcc}
\hline Table 1. Mean Age of Mothers According to Age Group & \\
\hline Age Group $(\mathbf{y})$ & No $(\%)$ & Mean Age \pm SD \\
\hline$<\mathbf{2 0}$ & $16(7)$ & $17 \pm 0.00$ \\
$\mathbf{2 0}-\mathbf{3 0}$ & $127(58)$ & $26.50 \pm 2.60$ \\
$>\mathbf{3 0}$ & $77(35)$ & $33.52 \pm 2.03$ \\
Total & $220(100)$ & $28.26 \pm 5.10$ \\
\hline
\end{tabular}

All participated mothers mentioned, at least, one sign and symptom associated with teething. The most common signs and symptoms mentioned by the respondents are presented in Table 3. The most and less common causes mentioned by the mothers were gum rubbing (91\%) and coryza (9\%). There is no correlation between the mothers' age groups and teething symptoms (Table 3 ).

\section{Discussion}

The timing of primary tooth eruption differs from 4 to 10 months of age. In $1 \%$ of the infants, the first deciduous tooth erupts before the age of 4 months; while, in $1 \%$ of the infants, no tooth eruption takes place until 12 months of age. In the present study, the timing of the tooth eruption was at the age of $7.16 \pm 1.60$ months. The minimum and maximum ages of tooth eruption were 4 and 14 months. All participated mothers mentioned, at least, one sign and symptom associated with teething. Attribution of some symptoms to teething has a long history. Although teething does not cause severe complications, much debate still exists as to influence of teething has on the child health. Primary teeth are also known as milk or deciduous teeth. The 20 primary teeth begin to appear in a baby's mouth about the sixth month and remain in the mouth until they are progressively replaced by the permanent teeth between the ages of six to twelve years. Primary teeth begin to develop from the 6th to 7th week of fetal life from epithelial cells of the mouth that form the tooth buds.

During pregnancy, the cells of these initial tooth germs begin to differentiate and most teeth are already partially developed in the jaws when the baby is born. (14).

Kakatkar et al. (15), found that the knowledge about teething was significantly associated with mothers' age so that the knowledge about teething increased with age. They also found this pattern with education, occupation, and income such that mothers with higher education, more income and having a job had more knowledge.

In addition, they also found that the urge to bite, gum pain, increased salivation, and loss of appetite were correctly reported by mothers as correlated with teething. But almost the majority of mothers mistakenly attributed teething to fever, diarrhea, and sleep disturbances, and often assumed that the process was not linked to systemic symptoms

In this regards, the present study that resulted the majority of mothers believed that gum rubbery, biting, irritability and fever were the symptoms of teething that is comparable with the Kakatkar et al., results.

In some studies, it has been recorded that the majority of parents assume that some signs of teething are present in their infants (16). In our research, the correlation of at 


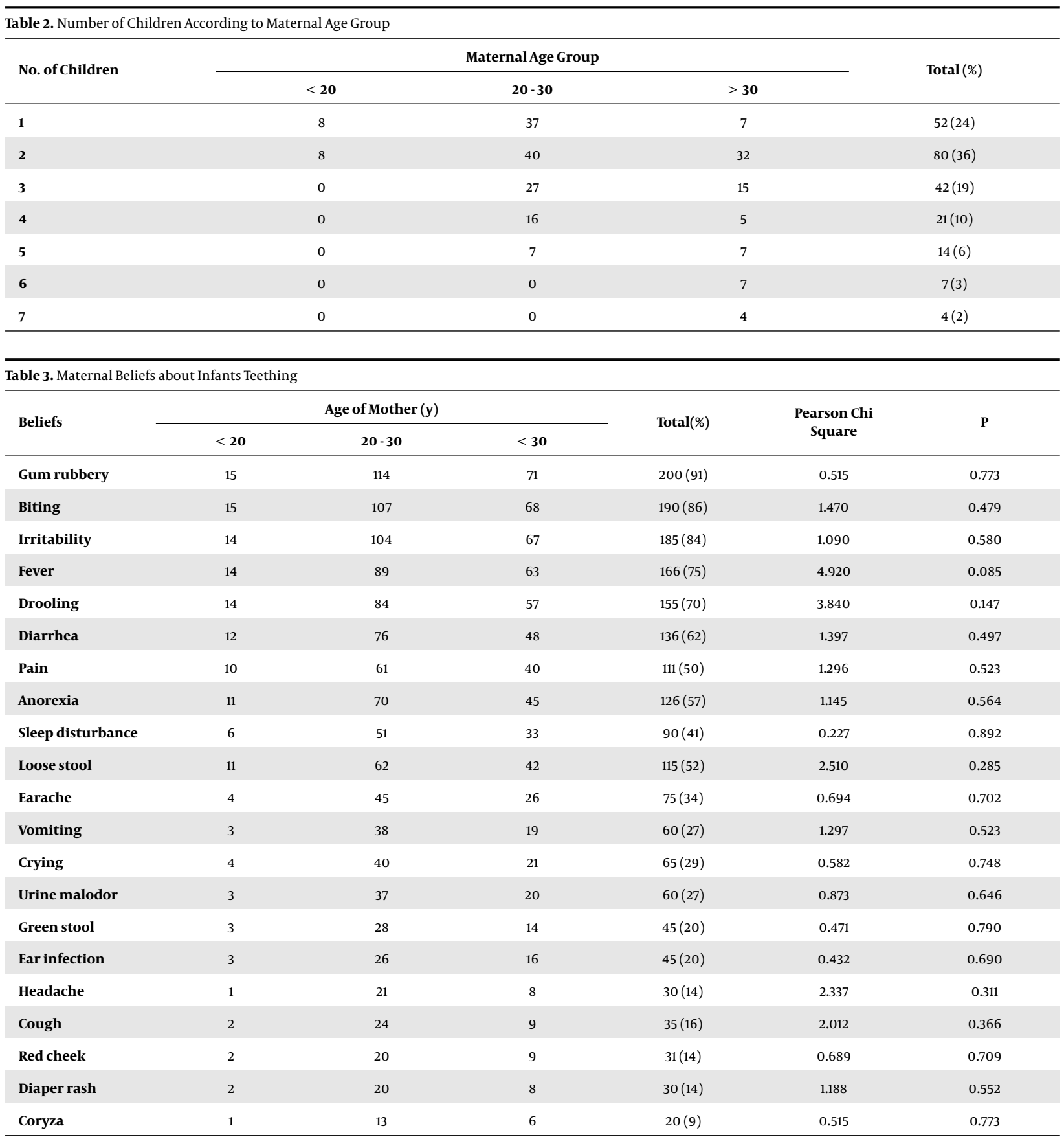

least one of the symptoms with teething was also believed by all mothers. This assumption persists not only among mothers, but also among physicians and child health practitioners, to preserve the connection of teething with such signs and symptoms. In a survey, it was found that most parents felt that some of the symptoms happened over the teething period. $(13,17)$.

In a study by Sarrell et al., it was found that $76 \%$ of the parents and $83 \%$ of the nurses believed that teething is associated with infant morbidity. The most common symptoms included of irritability, fever, diarrhea and loose stools, ear infection, vomiting, wheezing, and exacerbated asthma (5). From the present study found that the most common symptoms were gum rubbery, biting, irritability and fever with the percentages of $91 \%, 86 \%, 84 \%$ and $75 \%$ respectively. 
In a prospective cohort study, Wake et al. did not find association between fever, mood disorders, morbidity, sleep disturbances, drooling, diarrhea, smelly urine, red cheeks, rash, and flushing on the face or body with infants' teething (2).

In a study by Barlow et al., more than half of the parents and pediatric dentists believed that diarrhea is associated with teething (18).

In a study in Sudan, more than $90 \%$ of the mothers reported that teething was associated with diarrhea (19), which was more than the present study. In another study, the majority of the nurses believed that the loss of appetite, crying, increased salivation, and intensified irritation are a necessary part of teething process. In addition, $82 \%$ and $61 \%$ of them associated fever and diarrhea as the symptoms of teething, respectively (10).

In a study in Turkey, 98.8 percent of parents claimed that infants suffer from at least one of the symptoms listed, including an increased number of biting, and then increased irritability, restlessness, and fever, similar to our results, were identified as the most incident causes. (20).

In a prospective cohort study, it was determined that increased number of biting, drooling, irritability, ear rubbing, facial rash, decreased appetite for solid foods, and a slight increase in temperature are associated with teething (8). In a study by Wake et al., it was determined that the majority of the infants' parents believed that teething causes fever, pain, irritability, sleep disturbance, biting and mouthing, drooling, red cheeks (17). In another study, the most common teething symptoms were drooling (15\%), diarrhea (13\%), and diarrhea/drooling (8 percent). In 8 percent of the cases, fever and diarrhea were seen. Furthermore, most of the symptoms were found when the primary incisors began to erupt (21).

No signs or symptoms closely associated with teething were observed in a prospective study of 21 infants in Australia, which is not in line with many other clinical studies. (2). In a study by Macknin et al., no statistical association was found between symptoms cases as sleep disturbance, loose stools, increased number of stooling, decreased appetite for liquids, cough, rash on other parts of the body, fever greater than $102^{\circ} \mathrm{F}$, and vomiting with teething (10). A very few child health practitioners agree in another study that teething induces eczema, rashes, colic, convulsion, and constipation. (13). All the mothers in the present study connected a number of symptoms with infant teething. Regarding that such symptoms as severe fever, diarrhea, restlessness, and too much irritability is attributed to teething, this can distract parents from serious and dangerous diseases, leading to diagnosis and treatment delay. It is recommended to provide mothers with related trainings to visit doctors in case of appearance of such symptoms, and to evaluate the important and serious infectious and non-infectious causes for quick and appropriate treatment.

\subsection{Study limitation}

The study limitation was lack of proper mothers with inclusion criteria to participate in the study that made long time for reaching suitable sample size.

\section{Acknowledgments}

The authors would like to thank all mothers for their sincere agreement to take part in the study.

\section{Footnotes}

Authors' Contribution: Ghasem Miri-Aliabad: study concept, study design, and literature search,data acquisition. Ali Khajeh: manuscript editing. Alireza Teimouri: manuscript writing, statistical analysis.

Conflict of Interests: There is no conflict of interest of all the authors in this study.

Funding/Support: Zahedan University of Medical Sciences.

Informed Consent: informed consent from mothers were obtained.

\section{References}

1. Kreiborg S, Jensen BL. Tooth formation and eruption - lessons learnt from cleidocranial dysplasia. EurJOral Sci. 2018;126 Suppl 1:72-80. doi 10.1111/eos.12418. [PubMed: 30178560].

2. Wake $M$, Hesketh $\mathrm{K}$, Lucas J. Teething and tooth eruption in infants: A cohort study. Pediatrics. 2000;106(6):1374-9. doi: 10.1542/peds.106.6.1374. [PubMed: 11099591].

3. Shapira J, Berenstein-Ajzman G, Engelhard D, Cahan S, Kalickman I, Barak V. Cytokine levels in gingival crevicular fluid of erupting primary teeth correlated with systemic disturbances accompanying teething. Pediatr Dent. 2003;25(5):441-8. [PubMed: 14649607].

4. Lawoyin TO, Lawoyin DO, Lawoyin JO. Epidemiological study of some factors related to deciduous tooth eruption. Afr Dent J. 1996;10:19-23. [PubMed: 9590889].

5. Sarrell EM, Horev Z, Cohen Z, Cohen HA. Parents' and medical personnel's beliefs about infant teething. Patient Educ Couns. 2005;57(1):1225. doi: 10.1016/j.pec.2004.05.005. [PubMed:15797161].

6. McIntyre GT, McIntyre GM. Teething troubles? $\mathrm{Br}$ Dent $J$. 2002;192(5):251-5. doi:10.1038/sj.bdj.4801349. [PubMed:11924952].

7. Aliabad GM, Teimouri A, Noori N, Khajeh A. Beliefs of physicians and nurses toward infant teething: A cross sectional survey. Jentashapir $j$ health res. 2016;7(4). doi: 10.17795/jjhr-33504.

8. Macknin ML, Piedmonte M, Jacobs J, Skibinski C. Symptoms associated with infant teething: a prospective study. Pediatrics. 2000;105(4 Pt 1):747-52. doi: 10.1542/peds.105.4.747. [PubMed:10742315].

9. Anderson JE. " Nothing but the tooth": dispelling myths about teething. Contemp Pediatr. 2004;21(7):75-83. 
10. Bankole OO, Denloye OO, Aderinokun GA. Attitude, beliefs and practices of some Nigerian nurses toward teething in infants. Odontostom atol Trop. 2004;27(105):22-6. doi: 10.4314/wajm.v22i1.27974. [PubMed: 15281298].

11. Oziegbe EO, Folayan MO, Adekoya-Sofowora CA, Esan TA, Owotade FJ Teething problems and parental beliefs in Nigeria. J Contemp Dent Pract. 2009;10(4):75-82. [PubMed: 19575057].

12. Denloye O, Bankole OO, Aderinokun GA. Teething myths among community health officers. Odontostomatol Trop. 2005;28(109):19-22. [PubMed: 16032942]

13. Wake M, Hesketh K. Teething symptoms: cross sectional survey of five groups of child health professionals. BMJ. 2002;325(7368):814 doi: 10.1136/bmj.325.7368.814. [PubMed: 12376443]. [PubMed Central: PMC128949].

14. Begzati A, Berisha M, Mrasori S, Xhemajli-Latifi B, Prokshi R, Haliti F, et al. Early Childhood Caries (ECC) - Etiology, Clinical Consequences and Prevention. Emerging Trends In Oral Health Sciences And Dentistry. Viena, Austria: IntechOpen; 2015. p. 31-63.

15. Kakatkar G, Nagarajappa R, Bhat N, Prasad V, Sharda A, Asawa K. Parental beliefs about children's teething in Udaipur, India: a preliminary study. Braz Oral Res. 2012;26(2):151-7. doi: 10.1590/s1806-
83242012000200011. [PubMed: 22473351].

16. Ashley MP. It's only teething.A report of the myths and modern approaches to teething. Br Dent J. 2001;191(1):4-8. doi: 10.1038/sj.bdj.4801078. [PubMed: 11491477].

17. Wake M, Hesketh K, Allen M. Parent beliefs about infant teething: A survey of Australian parents. J Paediatr Child Health. 1999;35(5):446-9. doi: 10.1046/j.1440-1754.1999.355395.x. [PubMed: 10571756].

18. Barlow BS, Kanellis MJ, Slayton RL. Tooth eruption symptoms: a survey of parents and health professionals. ASDC JDent Child. 2002;69(2):14850.123-4. [PubMed: 12515056].

19. Ahmed IS, Eltom AR, Karrar ZA, Gibril AR. Knowledge, attitudes and practices of mothers regarding diarrhoea among children in a Sudanese rural community. East Afr Med J. 1994;71(11):716-9. [PubMed: 7859655].

20. Baykan Z, Sahin F, Beyazova U, Ozcakar B, Baykan A. Experience of Turkish parents about their infants' teething. Child Care Health Dev. 2004;30(4):331-6. doi: 10.1111/j.1365-2214.2004.00431.x. [PubMed: 15191423].

21. Peretz B, Ram D, Hermida L, Otero MM. Systemic manifestations during eruption of primary teeth in infants. J Dent Child (Chic). 2003;70(2):170-3. [PubMed: 14528780]. 